Research Article

\title{
Raphanus sativus L. Extract as a Scale and Corrosion Inhibitor for Mild Steel in Tap Water
}

\author{
G. Vasyliev (D, V. Vorobyova, and T. Zhuk \\ National Technical University of Ukraine "Igor Sikorsky Kyiv Polytechnic Institute", 37, Prospect Peremohy, Kyiv 03056, Ukraine \\ Correspondence should be addressed to G. Vasyliev; g.vasyliev@kpi.ua
}

Received 24 September 2019; Accepted 6 January 2020; Published 11 February 2020

Academic Editor: Khaled Mostafa

Copyright (c) 2020 G. Vasyliev et al. This is an open access article distributed under the Creative Commons Attribution License, which permits unrestricted use, distribution, and reproduction in any medium, provided the original work is properly cited.

\begin{abstract}
The Raphanus sativus L. ethanol extract was prepared by radish cake maceration in ethanol end tested as a scale and corrosion inhibitor of mild steel in tap water. Antiscalant efficiency was tested with electrochemical and thermal scaling techniques, and changes in hardness content were determined titrimetrically. No deposits were found on the metal surface at the extract concentration of $10 \mathrm{~mL} / \mathrm{L}$ in chronoamperometry test, and scaling suppression was established 5 times in thermal scaling conditions. The linear polarization resistance technique was used to determine corrosion rate. Inhibition efficiency was found to be $75 \%$ in thermal scaling conditions. The formation of the surface film was responsible for both scaling and corrosion suppression on mild steel surface as was established with FT-IR spectroscopy and SEM. The surface film was found to contain polymerization products of isothiocyanates.
\end{abstract}

\section{Introduction}

Utilization of natural water for both domestic and industrial purposes is related with scale and corrosion problems. Water containing dissolved gases such as $\mathrm{O}_{2}$ and $\mathrm{CO}_{2}$ can cause corrosion of metal equipment $[1,2]$, and the presence of $\mathrm{Ca}^{2+}$ and $\mathrm{Mg}^{2+}$ cations leads to scaling $[3,4]$, especially when water is used in heat exchange processes. As a result of corrosion, water quality deteriorates and metal equipment requires repairs and replacement more often. Scaling leads to extra fuel consumption and flow reduction. So, both the problems lead to economic losses and require the search of new efficient solutions.

The trend of today is application of "green" reagents that are environmentally friendly and biodegradable and can be obtained without any hazardous chemical synthesis [5-8]. Muryanto et al. studied malic acid as a scale inhibitor [9]. It was found that addition of malic acid in the concentration of 3-5 ppm reduces the scale mass 2 times and more. The formed crystals' morphology is also changed. Al-Roomi et al. tested novel low molecular weight copolymers (termed as YMR-series polymers) prepared through reaction of maleic anhydride as a new generation scale inhibitor [10]. They found that scale inhibition for steel and copper was up to 98\%. Peronno et al. investigated antiscaling properties of poly(acrylic acid-co-maleic acid) and polyaspartic acid [11]. Antiscaling efficiency was observed in the very low concentration of $4 \mathrm{mg} \cdot \mathrm{L}^{-1}$, and the scale structure was modified in the presence of an inhibitor. One of the promising sources of such reagents is natural extracts. Recently, the application of aqueous extract of Paronychia argentea [12], Spergularia rubra, and Parietaria officinalis aqueous solutions [13] as a scale inhibitor was reported. The proposed action mechanisms include complex formation with calcium ions that keep $\mathrm{Ca}^{2+}$ in the solution and prevent formation of $\mathrm{CaCO}_{3}$; also, inhibitor molecules are believed to be adsorbed on the growing crystals thus blocking them from $\mathrm{Ca}^{2+}$ supply.

Many "green" substances were tested as corrosion inhibitors. Ibrahimi et al. in their review analysed amino acids as corrosion inhibitors [14]. The main mechanism, similar to scale inhibition, was adsorption of inhibitor molecules on the metal surface and formation of the surface film that prevent oxygen ingress. Zhang tested synergistic effect of the combination of polyaspartic acid (PASP), polyepoxysuccinic acid (PESA), polyamino polyether methylenephosphonate (PAPEMP), sodium gluconate (Glu), and $\mathrm{Zn}^{2+}$ on carbon 
steel corrosion [15]. The formation of the protective film composed of adsorbed inhibitor molecules was confirmed with atomic force microscopy. Natural extracts were studied as corrosion inhibitors in water media [16]. Again, the formation of the surface film that acts as a diffusion barrier was responsible for corrosion inhibition.

Polymer materials were tested as combined scale and corrosion inhibitors. Liu synthesized acrylic acid-allylpolyethoxy carboxylate copolymer (AL15) and found it to be a good corrosion and scale inhibitor [17]. Migahed tested polyaspartic acid-glycine adduct for the same purpose [18]. Corrosion inhibition was $83.8 \%$, while scale inhibition was $-90.2 \%$. Wang et al. tested extract of tobacco rob as a scale and corrosion inhibitor [19]. Corrosion inhibition was caused by the formation of chemisorbed film on the steel, while scaling was inhibited mostly by the adsorption of inhibitor on the scale crystals.

In this study, Raphanus sativus L. extract was tested as a scale and corrosion inhibitor in tap water. Raphanus sativus L. is known to contain reducing sugars such as dextrose and sophorose, organic acids (mainly vanillic and gallic acids), anthocyanidins, and isothiocyanates (for example, iberverin and berteroin), and the formation of the surface film is highly expected.

\section{Experimental Section}

2.1. Extract Preparation. The extract was prepared by maceration of radish cake for $24 \mathrm{~h}$ in the ethanol. The raw material powder and ethanol were mixed in the weight ratio of $1: 10$. The resultant mixture was filtered with Whatman filter paper to remove solid contents.

2.2. GC-MS Extract Composition Analyses. Chemical composition of extract was analysed by GC-MS analysis (gas chromatography with a mass selective detector by mass selective integration). A Shimadzu gas chromatograph (model GC 17A) equipped with a flame ionization detector (FID) was operated under the following conditions: capillary fused silica column (CBP-5) (length, $25 \mathrm{~m}$; internal diameter, $0.25 \mathrm{~mm}$; film thickness, $0.22 \mu \mathrm{m}$ ) and ion source temperature of $280^{\circ} \mathrm{C}$. The GC-MS was operated in the electron impact ionization mode (EI) at $70 \mathrm{eV}$. The oven temperature was programmed as follows: the initial temperature of $50^{\circ} \mathrm{C}$ was maintained for $2 \mathrm{~min}$ and then increased to $200^{\circ} \mathrm{C}$ at the rate of $10^{\circ} \mathrm{C} / \mathrm{min}$ and held for $5 \mathrm{~min}$. Afterwards, the temperature was ramped to $250^{\circ} \mathrm{C}$ at the rate of $25^{\circ} \mathrm{C} / \mathrm{min}$ (for $15 \mathrm{~min}$ ). Other operating conditions included the following: carrier gas, $\mathrm{He}(99.99 \%)$, inlet pressure $76 \mathrm{kPa}$, with a linear velocity of $20 \mathrm{~cm} / \mathrm{s}$; injector temperature $250^{\circ} \mathrm{C}$; detector temperature $310^{\circ} \mathrm{C}$; and split ratio $1: 25$. The relative contents of the chemical components of the extract were found with the help of the method of internal normalization of the areas of peaks without correcting the sensitivity coefficients. The percentage of each compound was determined from its peak area and the sum of the areas of all peaks detected in the total ion current (TIC) trace. The identification and quantification of the components was carried out by using commercially available databases: Nist 05 (National Institute of Standards and Technology, USA) and Mass Finder3 (Dr. Hochmut, Scientific Consulting, Germany).

2.3. Chronoamperometry. Electrochemical technique of chronoamperometry is a fast and convenient approach to study scaling processes $[1,2]$. The working electrode is polarized at a constant negative potential of $-1.1 \mathrm{~V} / \mathrm{SSCE}$ (saturated silver chloride electrode $E=0.2 \mathrm{~V} / \mathrm{NHE}$ ). At this potential, the dissolved oxygen is reduced to $\mathrm{OH}^{-}$ions causing the alkalization of the pre-electrode layer. The carbonic equilibrium is shifted to form carbonates, and $\mathrm{CaCO}_{3}$ is deposited on the electrode surface:

$$
\begin{aligned}
\mathrm{O}_{2}+2 \mathrm{H}_{2} \mathrm{O}+4 e & =4 \mathrm{OH}^{-} \\
\mathrm{HCO}_{3}^{-}+\mathrm{OH}^{-} & =\mathrm{CO}_{3}^{2-}+\mathrm{H}_{2} \mathrm{O}
\end{aligned}
$$

The current reduction means the scale is formed on the electrode surface; meanwhile, the unchanged current value means no scale is deposited. Also, the current-time dependence provides the information of scaling time $t_{s}$ (theoretical time value, needed to fully cover the electrode surface) and scale porosity SP (the ratio between residual and initial current values).

Chronoamperometry tests were performed in a conventional three-electrode electrochemical cell. The working electrode was a mild steel cylinder (diameter, $6 \mathrm{~mm}$; length, $30 \mathrm{~mm}$ ) rotated at $500 \mathrm{rpm}$. The electrode surface was mechanically abraded with P600 emery paper, degreased, and etched in $200 \mathrm{~g} / \mathrm{l} \mathrm{HCl}$ prior to the test. A counter electrode, platinum grid, and a saturated silver chloride electrode were as reference one. The tap water (composition is given in Table 1) of 11 volume was kept at $25 \pm 0.5^{\circ} \mathrm{C}$ during the test. The mass of the deposited carbonates was determined by weighing the working electrode before and after electrochemical measurements with $0.0001 \mathrm{~g}$ accuracy. Polarization continued for $3 \mathrm{~h}$. Each test was repeated 3 times, and the data were averaged.

2.4. Thermal Scaling. Antiscalant efficiency of the extract was also tested in thermal scaling conditions. The scale was deposited on the surface of the steel rings placed on top of the Pyrex glass tube. The heating spiral was placed inside the tube and connected to the electric transformer. The electric power of the spiral was $70 \mathrm{~W}$. The tube with steel rings was placed inside the glass beaker filled with tap water. The beaker was covered on the top to prevent solution evaporation. The water was replaced daily.

The scale growth rate with and without antiscalant was determined by weighing the tube every 20 hours of boiling.

The ability of the extract to form water-soluble complexes with hardness cations was tested titrimetrically. For this purpose, water hardness was determined titrimetrically before and after daily test. A solution sample was buffered to $\mathrm{pH}$ 10.1, the indicator was added, and EDTA was used as the 
TABLE 1: Water chemical composition.

\begin{tabular}{lccc}
\hline Parameter & & Units & Value \\
\hline $\mathrm{pH}$ & & & $7.8-8.0$ \\
Dissolved oxygen & $\mathrm{DO}$ & $\mathrm{mg} / \mathrm{L}$ & 6.0 \\
Total hardness & $\mathrm{TH}$ & $\mathrm{mmol} / \mathrm{L}$ & $3.9-4.2$ \\
Total alkalinity & $\mathrm{TA}$ & $\mathrm{mmol} / \mathrm{L}$ & $3.9-4.1$ \\
Calcium & $\mathrm{Ca}^{2+}$ & $\mathrm{mmol} / \mathrm{L}$ & $3.0-3.1$ \\
Magnesium & $\mathrm{Mg}^{2+}$ & $\mathrm{mmol} / \mathrm{L}$ & $0.9-1.1$ \\
Chloride & $\mathrm{Cl}^{-}$ & $\mathrm{mg} / \mathrm{L}$ & $18-25$ \\
Sulphate & $\mathrm{SO}_{4}{ }^{2-}$ & $\mathrm{mg} / \mathrm{L}$ & $30-35$ \\
Hydrocarbonate & $\mathrm{HCO}_{3}{ }^{-}$ & $\mathrm{mmol} / \mathrm{L}$ & $3.2-3.5$ \\
Total dissolved solids & $\mathrm{TDS}$ & $\mathrm{mg} / \mathrm{L}$ & $240-260$ \\
\hline
\end{tabular}

titrant. Antiscaling efficiency due to complex formation $\eta$ was calculated according to the following formula:

$$
\eta=\frac{\rho_{2}-\rho_{0}}{\rho_{1}-\rho_{0}} \times 100 \%,
$$

where $\rho_{0}$ is the solution hardness before heating, $\rho_{1}$ is the solution hardness after heating without antiscalant, and $\rho_{2}$ is the solution hardness after heating with antiscalant.

2.5. Polarization Resistance Measurement. Corrosion inhibition efficiency of the extract was determined with the linear polarization resistance (LPR) technique in thermal scaling conditions [20-22]. The pair of steel rings placed on the Pyrex tube was electrically connected to corrometer and worked as a corrosion probe. LPR was measured every $15 \mathrm{~min}$ in a galvanostatic mode: the current density of $5 \mu \mathrm{A} /$ $\mathrm{cm}^{2}$ was applied to the probe, and the potential shift was measured after $30 \mathrm{~s}$ [23]. The initial potential difference and ohmic drop were automatically compensated, and the polarization resistance value was recalculated into steel corrosion rate with Stern's equation using the conventional $B$ value of $26 \mathrm{mV}$ [24].

2.6. Scale Characterization. The morphology of the surface after thermal scaling was studied using a SEM-106I Selmi microscope (Ukraine) operated at $20 \mathrm{kV}$. The steel rings were removed from the Pyrex tube, dried, and sent to analyses.

FT-IR spectroscopy was performed to determine the main groups in the extract and the formed surface layer. The scale from the steel rings was scraped off with a surgery blade and sent to FT-IR. Fourier transform infrared spectroscopy (FT-IR) spectra were recorded on a FT-IR spectrometer (Thermo Scientific Nicolet 6700 FT-IR spectrometer (spectral resolution $0.5 \mathrm{~cm}^{-1}$ )) using the $\mathrm{KBr}$ pellet technique. Spectra were recorded over $450-4000 \mathrm{~cm}^{-1}$.

\section{Results and Discussion}

3.1. GC-MS and FT-IR Analysis of Extract. GC-MS was used to identify the organic compounds present in the radish cake extract (RCE). The GC-MS spectra of the RCE show prominent peaks (Figure 1) which are mentioned in Table 2. The chemical molecular structures of the predominant compounds identified in the studied radish cake extract are presented in Table 3. Anthocyanidins including cyanidin $(6.7 \%)$ and pelargonidin (6.9\%) and isothiocyanates such as 3-(methylthio)propyl isothiocyanate (iberverin) (4.2\%), 4pentenyl isothiocyanate (8.3\%), 4-methylpentyl isothiocyanate $(3.1 \%)$, 3-butenyl isothiocyanate $(3.9 \%)$, 4(methylthio)-3-butenyl isothiocyanate (5.2\%), 4-(methylthio)butyl isothiocyanate (erucin) (6.4\%), 5-(methylthio) pentyl isothiocyanate (berteroin) (6.9\%), and L-sulforaphane $(1.1 \%)$ were identified in RCE. 4-Pentenyl isothiocyanate and 5-(methylthio)pentyl isothiocyanate were found in large amounts in the radish cake extract sample. Other major compounds including phenolic derivatives such as pyrogallol, vanillic and gallic acids, and eugenol were also detected together with some fatty acids in considerable amount (8.9\%).

Figure 7 shows the FT-IR spectra of the RCE. The typical $\nu(\mathrm{C}=\mathrm{O})$ vibration of carboxylic acids (vanillic and gallic acids) is observed as a very strong IR band at $1652 \mathrm{~cm}^{-1}$. The bands at 1045 and $1299 \mathrm{~cm}^{-1}$ are attributed to $\mathrm{C}-\mathrm{O}-\mathrm{C}$ vibrations of glycoside content. The bands around $2900-2950 \mathrm{~cm}^{-1}$ are attributed to C-H stretching including $\mathrm{CH}, \mathrm{CH}_{2}$, and $\mathrm{CH}_{3}$ bending vibrations. The infrared absorption in the spectral range between 1500 and $1300 \mathrm{~cm}^{-1}$ contains vibrations of fatty acids. The peaks at 2938 and $2986 \mathrm{~cm}^{-1}$ can be assigned to the $\mathrm{N}=\mathrm{C}=\mathrm{S}$ symmetric and asymmetric stretches. The framework vibration of pyridine ring and stretching mode of $\mathrm{C}=\mathrm{N}$ indicates the presence of isothiocyanates. The results indicate that RCE may contain mixtures of compounds such as anthocyanidins, isothiocyanates, and phenolic derivatives. These compounds could contribute to the anticorrosion properties of the extract, and they were also noted to be present in an earlier study [25-29].

3.1.1. Electrochemical Scaling Test. The normalized chronoamperometric curves obtained for the radish cake extract in concentrations of 1 and $10 \mathrm{~mL} / \mathrm{L}$ are given at Figure 2. The curve for tap water is also provided for reference. The extract of $1 \mathrm{~mL} / \mathrm{L}$ concentration slows the crystallization, and at $10 \mathrm{~mL} / \mathrm{L}$, the current is reduced nearly 4 times. The radish cake extract in $1 \mathrm{~mL} / \mathrm{L}$ concentration increases $t_{\mathrm{s}}$ to $3600 \mathrm{~s}$, but at a higher concentration of $10 \mathrm{~mL} / \mathrm{L}, t_{\mathrm{s}}$ is reduced to $1000 \mathrm{~s}$. Also, the shape of current-time dependence in the concentration of $10 \mathrm{~mL} / \mathrm{L}$ is changed. It shows fast current 


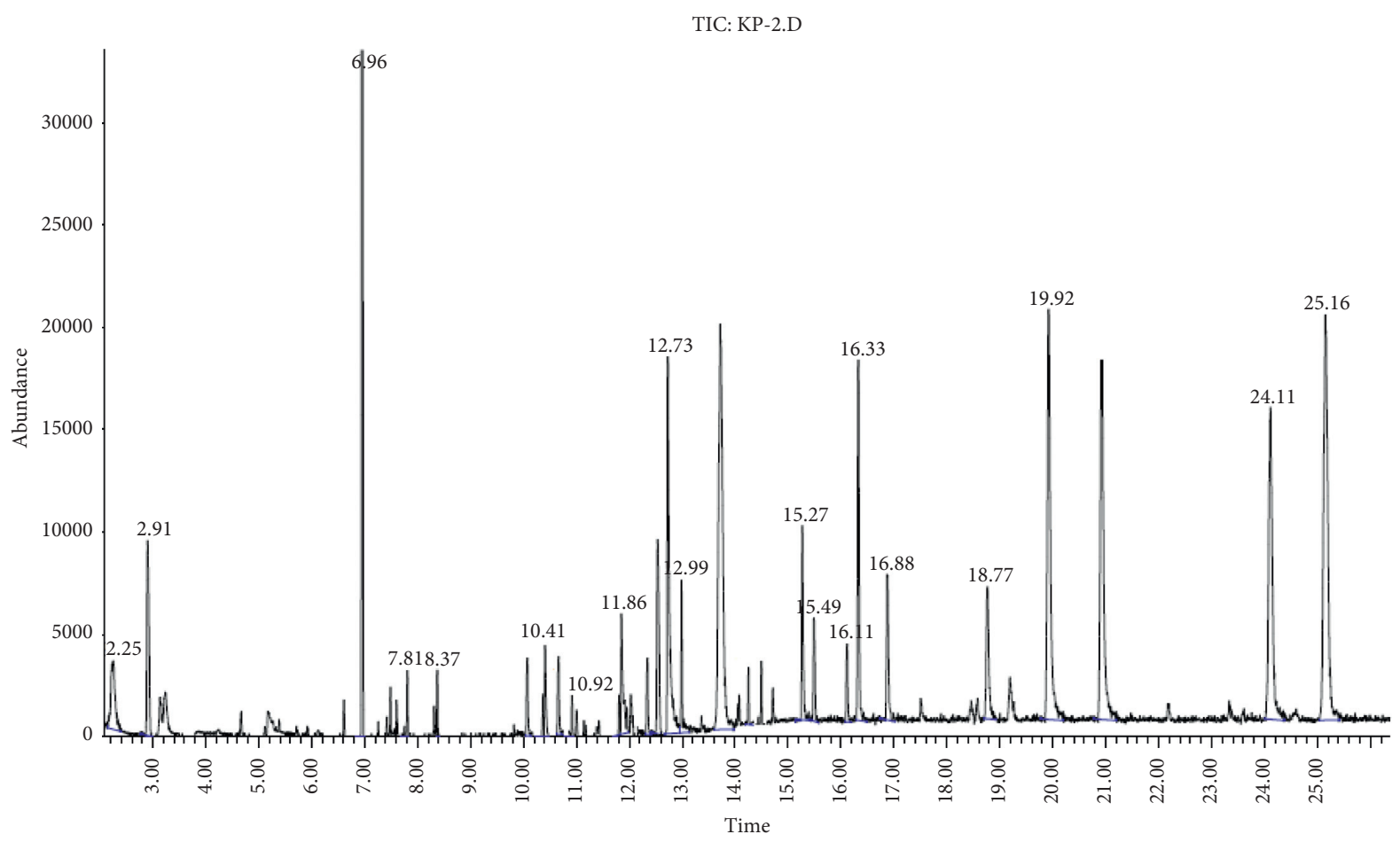

FIGURE 1: GC-MS spectra of the radish cake ethanol extract.

TABLE 2: Composition of the radish cake extract according to GC-MS analysis.

\begin{tabular}{|c|c|c|c|}
\hline Holding time, $t$ (min) & Name of the component & Weight ratio (\%) & Molecular weight \\
\hline 2.91 & 3-(Methylthio)propyl isothiocyanate (iberverin) & 4.2 & 147.01 \\
\hline 3.02 & Pyrogallol acids & 2.9 & 126.03 \\
\hline 6.96 & 4-Pentenyl isothiocyanate & 8.3 & 127.04 \\
\hline 7.31 & 4-Methylpentyl isothiocyanate & 3.1 & 143.07 \\
\hline 10.02 & Undecane & 1.9 & 156.18 \\
\hline 10.41 & Eugenol & 2.5 & 164.08 \\
\hline 10.62 & Vanillic acid & 2.8 & 168.04 \\
\hline 10.92 & Dodecane & 1.0 & 170.33 \\
\hline 11.86 & 3-Butenyl isothiocyanate & 3.9 & 113.18 \\
\hline 12.42 & 4-(Methylthio)-3-butenyl isothiocyanate & 5.2 & 159.01 \\
\hline 12.73 & 4-(Methylthio)butyl isothiocyanate (erucin) & 6.4 & 161.03 \\
\hline 12.99 & Gallic acid & 2.7 & 170.02 \\
\hline 13.78 & 5-(Methylthio)pentyl isothiocyanate (berteroin) & 6.9 & 175.04 \\
\hline 14.24 & L-sulforaphane & 1.1 & 177.02 \\
\hline 15.27 & Dextrose & 3.7 & 180.15 \\
\hline 15.49 & Tridecane & 1.9 & 184.21 \\
\hline 16.11 & Dodecanoic acid (lauric acid) & 0.8 & 200.31 \\
\hline 16.33 & Cyanidin & 6.7 & 287.24 \\
\hline 18.77 & Hexadecenoic acid (palmitic acid) & 2.2 & 256.24 \\
\hline 19.92 & Pelargonidin & 6.9 & 271.24 \\
\hline 21.00 & Octadecanoic acid & 5.9 & 356.31 \\
\hline 24.11 & Methyl linoleate & 5.1 & 294.50 \\
\hline 25.16 & Sophorose & 7.1 & 342.30 \\
\hline
\end{tabular}

decrease during the first $1000 \mathrm{~s}$, and after stabilization, the current remains unchanged. At the concentration of $1 \mathrm{~mL} / \mathrm{L}$, the current decreases slowly during the entire test.

Values of surface porosity SP, scaling time $t_{\mathrm{s}}$, and area density are collected in Table 4 . In $1 \mathrm{~mL} / \mathrm{L}$ concentration, scale porosity values are above $6 \%$. At $10 \mathrm{~mL} / \mathrm{L}$ concentration, porosity is nearly $20 \%$ indicating weak blocking abilities of the layer. The area density values show that the extracts at $1 \mathrm{~mL} / \mathrm{L}$ concentration do not reduce the mass of the scale deposited on the surface. Moreover, the mass of the scale is even higher due to longer crystallization period. At $10 \mathrm{~mL} / \mathrm{L}$ concentration, the radish cake extract 
TABLe 3: Chemical structures of the main chemical constituents of the radish cake extract.<smiles>C=CCCCN=C=S</smiles>

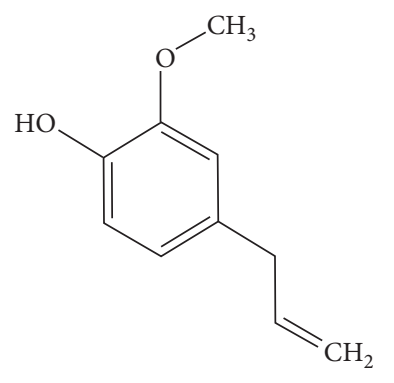

Eugenol<smiles>Oc1cc(O)c2cc(O)c(-c3ccc(O)c(O)c3)[o+]c2c1</smiles>

Cyanidin<smiles>O=C(O)c1cc(O)c(O)c(O)c1</smiles>

Gallic acid

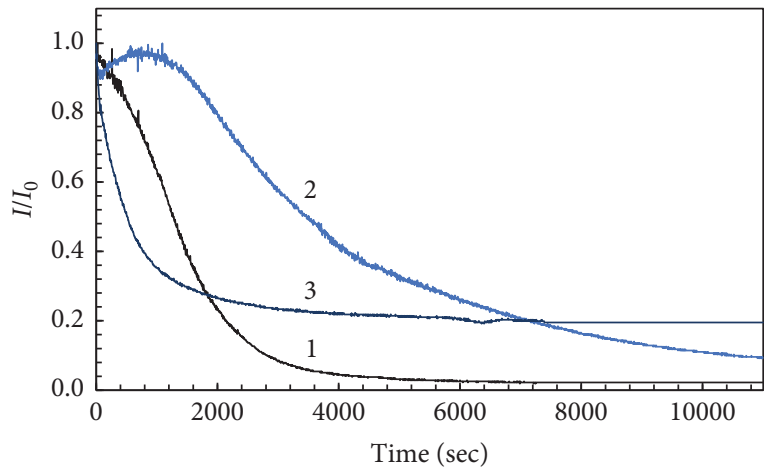

FIGURE 2: Normalized chronoamperometric curves of the electrochemical scaling process in tap water at $25^{\circ} \mathrm{C}$ in the presence of the radish cake extract: 1 , no extract; $2,1 \mathrm{~mL} / \mathrm{L}$ extract; $3,10 \mathrm{~mL} / \mathrm{L}$ extract.

prevents crystallization. Practically, no changes in the electrode weight were detected.

3.1.2. Thermal Scaling Test. The mass of the scale on the surface of mild steel is given in Figure 3. The deposition rate in tap water is $7.5 \mu \mathrm{g} /\left(\mathrm{h} \cdot \mathrm{cm}^{2}\right)$. It remains constant during the first $130 \mathrm{~h}$ and then slightly decreases. In contrast to tap water, when the extract is added, the scale deposition is reduced to $1.6 \mu \mathrm{g} /\left(\mathrm{h} \cdot \mathrm{cm}^{2}\right)$ meaning antiscaling efficiency is $78.7 \%$. So, the RCE slows down deposition of calcium carbonate even at the temperature of $100^{\circ} \mathrm{C}$.

Possible mechanism of scale inhibition could be the formation of soluble complexes with calcium ions. Such complexes prevent the deposition of calcium carbonate keeping calcium ions in the soluble form. According to GCMS, phenolic derivatives such as pyrogallol, vanillic and gallic acids, eugenol, and polysaccharides are found in the extract [30-32]. The mechanisms for scale inhibition by the radish cake extract are associated with active functional groups $(\mathrm{C}=\mathrm{O},-\mathrm{OH},-\mathrm{COOH}$, and $\mathrm{N}=\mathrm{C}=\mathrm{S}$ groups $)$ of the
TABLE 4: Scale parameters obtained in the electrochemical scaling test.

\begin{tabular}{lccc}
\hline \multirow{2}{*}{ Parameter } & \multicolumn{3}{c}{ Extract concentration $(\mathrm{mL} / \mathrm{L})$} \\
& 0 (tap water) & 1 & 10 \\
\hline Scale porosity, SP $(\%)$ & 2.33 & 6.58 & 19.54 \\
Scaling time, $t_{\mathrm{s}}(\mathrm{s})$ & 2400 & 3600 & $(1000)$ \\
Area density $\left(\mathrm{mg} / \mathrm{cm}^{2}\right)$ & 0.50 & 0.74 & 0.03 \\
\hline
\end{tabular}

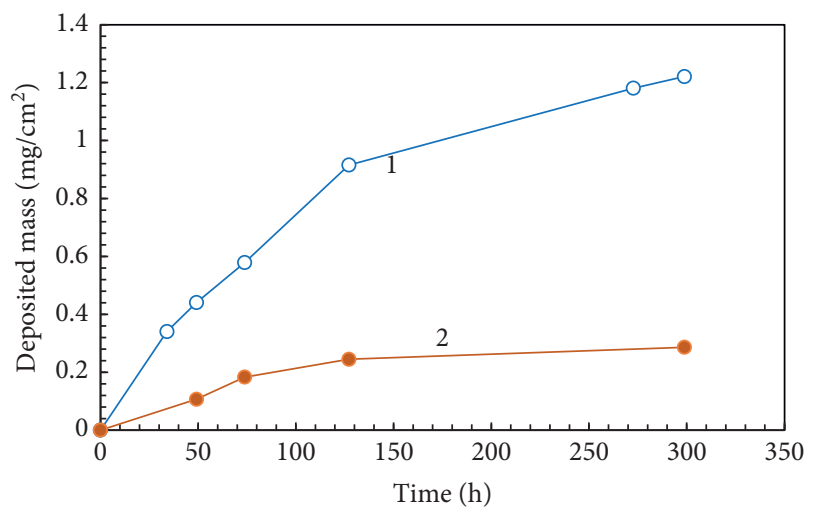

Figure 3: Scaling rate of mild steel in tap water at $100^{\circ} \mathrm{C}$ : 1 , blank; 2 , with $10 \mathrm{~mL} / \mathrm{L}$ of radish cake extract.

main compounds of the extract. These substances, which have hydroxyl and/or carboxyl functional groups that interact with divalent ions such as $\mathrm{Ca}^{2+}$, are known to form water-soluble complexes with calcium ions. In addition to this, carboxylterminated anthocyanidins have a larger surface area, which can chelate with more $\mathrm{Ca}^{2+}$. Therefore, the radish cake extract could prevent the formation of calcium carbonate via formation of water-soluble complexes.

Scale inhibition was determined from the change of hardness salt concentration in one-day run in tap water 
solution and with different RCE concentrations (Figure 4). It was found that the antiscaling efficiency according to the changes in hardness is only $52 \%$. In contrast, the mass of the deposited scale is nearly 5 times lower when the extract is added to the solution. This means that soluble complex formation only could not explain antiscaling efficiency of the extract.

3.1.3. Corrosion Inhibition. The instantaneous corrosion rate of mild steel determined with the LPR technique in thermal scaling conditions is given in Figure 5. In tap water, the corrosion rate of mild steel right after immersion is around $0.8 \mathrm{~mm} /$ year and decreases with the boiling time due to the formation of the scale layer that acts as a diffusion barrier and reduces oxygen supply to the surface. In tap water with RCE, the corrosion rate decreases in the first hour and reaches the value of $0.2 \mathrm{~mm} /$ year meaning corrosion inhibition efficiency is $75 \%$. So, RCE provides efficient corrosion protection on the steel surface. As scale deposition progresses, corrosion rate in both tap water and inhibited solution decreases; however, in tap water, the decrease is faster because more scale is deposited. The thicker the scale layer, the less porous it becomes; thus, the corrosion rate is lower. After $50 \mathrm{~h}$ of boiling, the corrosion rate in both solutions coincides at $0.2 \mathrm{~mm} /$ year and continues to decrease till the corrosion rate of $0.1 \mathrm{~mm} /$ year is reached.

3.1.4. Surface Film Formation. The analyses of chronoamperometric curves (Figure 1) suggest that in the $10 \mathrm{~mL} /$ $\mathrm{L}$ concentration, when no scale is deposited, the current is reduced due to the formation of the surface film. This film consists of extract components and acts as a barrier protecting the steel surface from the supply of both calcium carbonate and dissolved oxygen.

The SEM images of the scaled steel surface are given in Figure 6. The scale deposited from tap water has a regular structure. The crystals are $60-80 \mu \mathrm{m}$, and the layer is uniform. In the presence of RCE, the crystals are much smaller and the presence of the organic film is clearly observed on the surface. Figure 6(c) demonstrates the charging effect of SEM when the electrons are accumulated in the organic film. SEM analysis clearly demonstrates the formation of the organic surface film that acts as a barrier level to reduce the supply of oxygen and calcium carbonate, thus reducing scaling and corrosion.

To identify the nature of the film, the scale after deposition was analysed with FT-IR (Figure 7). Comparison of the FT-IR spectra of the radish cake extract, the scale film, and scale film after exposure in inhibited solution in the presence of RCE showed that the spectra were changed to a different extent (Table 5). As shown by curve (1), the peaks given at 873 and $712 \mathrm{~cm}^{-1}$ could be attributed to the vibrations of calcite of $\mathrm{CaCO}_{3}$ crystal polymorphs, the peak at $1402 \mathrm{~cm}^{-1}$ reflect vaterite of $\mathrm{CaCO}_{3}$ crystal polymorphs. The absorption peak at $712 \mathrm{~cm}^{-1}, 870 \mathrm{~cm}^{-1}$, and $1402 \mathrm{~cm}^{-1} \mathrm{de}-$ creases in curve (2), indicating the antiscalant efficiency of the extract.

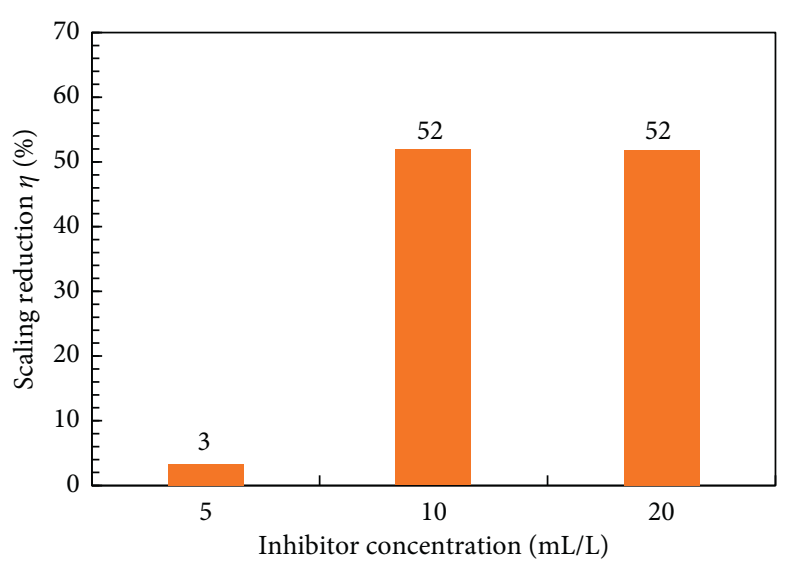

FIGURE 4: Scale inhibition efficiency titration test.
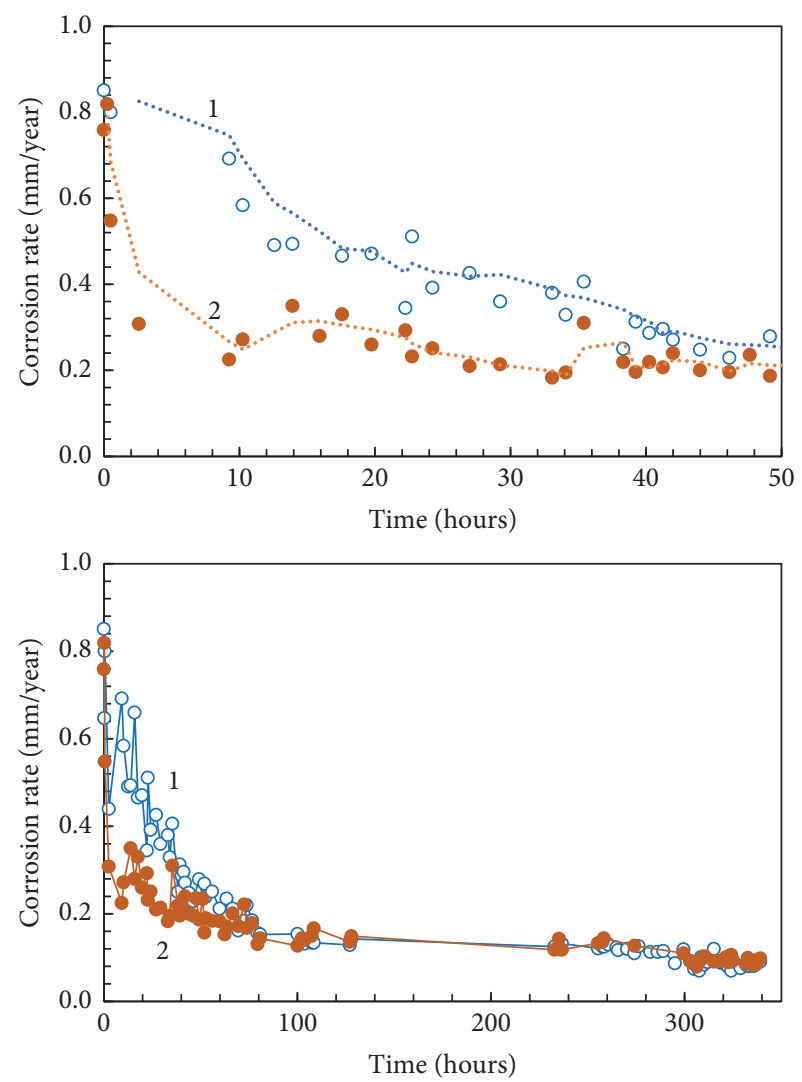

FIGURE 5: LPR corrosion rate of mild steel in tap water at $100^{\circ} \mathrm{C}$ : 1 , blank; 2, with $10 \mathrm{~mL} / \mathrm{L}$ radish cake extract.

The extended peak in the range around $1200-1400 \mathrm{~cm}^{-1}$ indicates that phenolic compounds and isothiocyanates were adsorbed on the steel surface. This indicates that probably these compounds may be responsible for scale inhibition.

The bands around $2200-2400 \mathrm{~cm}^{-1}$ are attributed to polymeric bond types $((\mathrm{C}=\mathrm{C})$ stretching vibration) $[25,26,29]$. Isothiocyanates are known to be heterocumulenes with an electrophilic centre on the carbon atom. Therefore, nucleophilic addition reactions are typical for them. For many heterocumulenes, the reactions of $[2+2]$, 


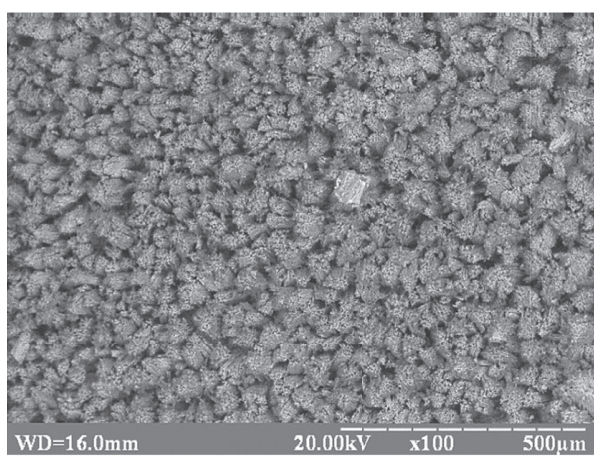

(a)

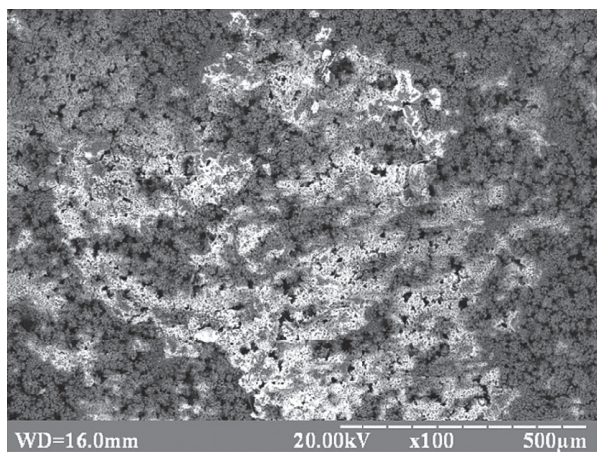

(c)

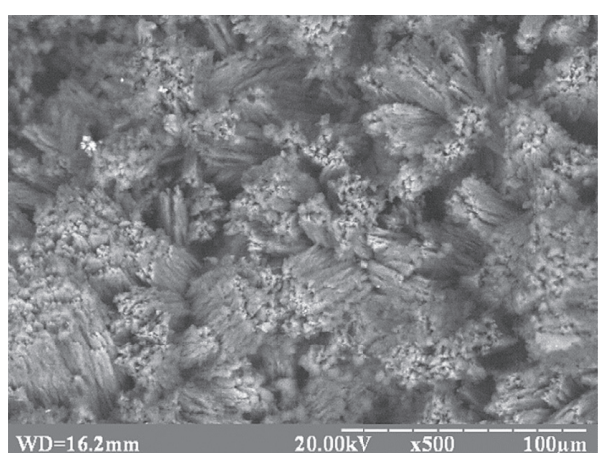

(b)

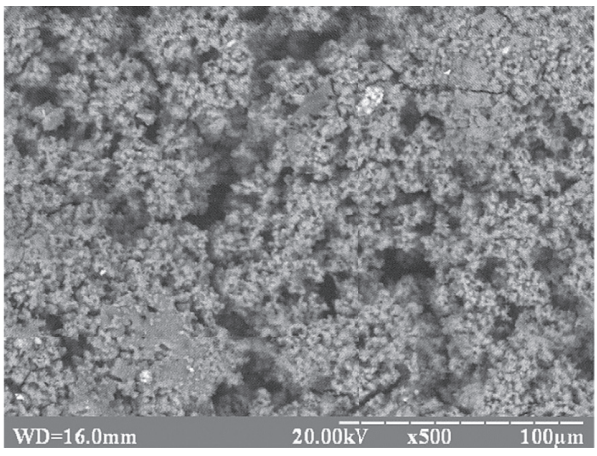

(d)

FiguRE 6: SEM images of the scaled surface at different magnification: (a) and (b), tap water; (c) and (d), tap water with $10 \mathrm{~mL} / \mathrm{L}$ of the radish cake extract.

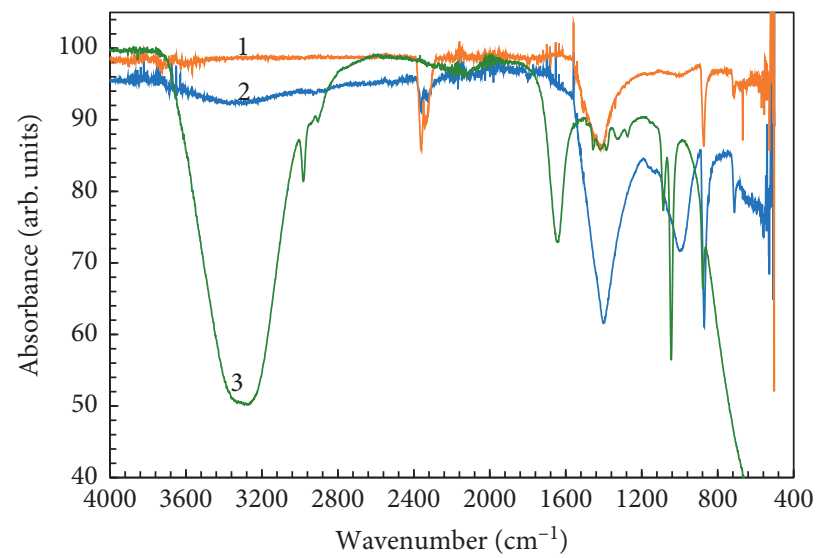

FIGURE 7: FT-IR spectra of crystalline calcium carbonate grown in the absence of RCE (1), presence of RCE (2), and radish cake extract (3).

TABLE 5: Peaks from FT-IR spectra samples: RCE (a), the scale film (b), and scale film after exposure in the presence of RCE (c).

\begin{tabular}{|c|c|c|c|}
\hline \multicolumn{3}{|l|}{ Wavenumber $\left(\mathrm{cm}^{-1}\right)$} & \multirow{2}{*}{ Possible groups } \\
\hline RCE & Scale film in RCE & Scale film & \\
\hline 3291 & & - & $\mathrm{O}-\mathrm{H} / \mathrm{N}-\mathrm{H}$ \\
\hline 2981, 2902 & & - & Aliphatic, aromatic $\mathrm{C}-\mathrm{H}$ or $\mathrm{N}=\mathrm{C}=\mathrm{S}$ \\
\hline $1456,1417,1639$ & & - & $\mathrm{C}=\mathrm{O}$ or $\mathrm{C}=\mathrm{N}$ \\
\hline $1084,1384,1326,1273$ & & - & $\mathrm{C}-\mathrm{O}-\mathrm{C}$ \\
\hline- & 2336 & - & $\mathrm{C}=\mathrm{C}$ \\
\hline- & 716 & 713 & Calcite \\
\hline - & 873 & 870 & \\
\hline- & 1402 & 1400 & Vaterite \\
\hline
\end{tabular}


cycloaddition with the formation of four-membered cycles are common. As a result, isocyanates dimerize to form uretdiones. It is possible that the formation of a partially polymerized type of film causes a high antiscalant action.

The mechanisms for scale inhibition of the radish cake extract have been associated with both formation of the protective film on the surface of steel by compounds such as isothiocyanates and saturated fatty acids and formation of water-soluble complexes of the phenolic derivatives (pyrogallol, vanillic and gallic acids, eugenol, and polysaccharides) with divalent ions $\mathrm{Ca}^{2+}$. The investigation of the scale and corrosion inhibition mechanism of the radish cake extract has indicated that because of multicomponent composition, it provides complexation ability with calcium ions and absorption ability on the steel surface that prevent the formation of calcium scale crystals and assure the corrosion inhibition effectively $[25,26,29]$.

\section{Conclusions}

The ethanol extract of radish cake was tested as a scale and corrosion inhibitor of mild steel in tap water. The following conclusions can be formulated:

(1) According to GC-MS and FT-IR analyses, the main components of the extract are as follows: isothiocyanates (39.1\%), phenolic derivatives $(10.9 \%)$, anthocyanidins (13.6\%), and saturated fatty acids $(8.9 \%)$.

(2) The thermal scaling test revealed that the radish cake extract in a concentration of $10 \mathrm{~mL} / \mathrm{L}$ can suppress scaling 4.7 times. At the same time, the corrosion inhibition efficiency is $75 \%$. The scaling and corrosion are both suppressed due to the formation of the film on the surface of steel. This film acts as a barrier layer preventing oxygen and calcium carbonate ingress to the surface.

(3) The presence of the film was confirmed with SEM and FT-IR analyses. The film is mainly composed of phenolic derivatives and isothiocyanates formed by extract components and their products of chemical transformation that partially polymerized.

\section{Data Availability}

The GS-MS, LPR, and chronoamperometric data used to support the findings of this study are included within the article.

\section{Conflicts of Interest}

The authors declare that they have no conflicts of interest.

\section{Acknowledgments}

This work was supported by the Ministry of Education and Science of Ukraine (grant nos. 2044 and 2017).

\section{References}

[1] G. S. Vasyliev, "The influence of flow rate on corrosion of mild steel in hot tap water," Corrosion Science, vol. 98, pp. 33-39, 2015.

[2] G. Vasyliev, A. Brovchenko, and Y. Herasymenko, "Comparative assessment of corrosion behaviour of mild steels 3, 20 and 08KP in tap water," Chemistry and Chemical Technology, vol. 7, no. 4, pp. 477-482, 2013.

[3] G. S. Vasyliev and S. M. Vasylieva, "The influence of ultrasound on the carbonate cathodic crystallization in artificial potable water," Journal of The Electrochemical Society, vol. 164, no. 4, pp. H250-H256, 2017.

[4] G. Vasyliev, S. Vasylieva, A. Novosad, and Y. Gerasymenko, "Ultrasonic modification of carbonate scale electrochemically deposited in tap water," Ultrasonics Sonochemistry, vol. 48, pp. 57-63, 2018.

[5] M. Chaussemier, E. Pourmohtasham, D. Gelus et al., "State of art of natural inhibitors of calcium carbonate scaling. A review article," Desalination, vol. 356, pp. 47-55, 2015.

[6] D. Hasson, H. Shemer, and A. Sher, "State of the art of friendly "green" scale control inhibitors: a review article," Industrial and Engineering Chemistry Research, vol. 50, no. 12, pp. 7601-7607, 2011.

[7] J. Li, M. Tang, Z. Ye, L. Chen, and Y. Zhou, "Scale formation and control in oil and gas fields: a review," Journal of Dispersion Science and Technology, vol. 38, no. 5, pp. 661-670, 2017.

[8] R. Menzri, S. Ghizellaoui, and M. Tlili, "Calcium carbonate inhibition by green inhibitors: thiamine and pyridoxine," Desalination, vol. 404, pp. 147-154, 2017.

[9] S. Muryanto, A. P. Bayuseno, H. Ma'mun, M. Usamah, and Jotho, "Calcium carbonate scale formation in pipes: effect of flow rates, temperature, and malic acid as additives on the mass and morphology of the scale," Procedia Chemistry, vol. 9, pp. 69-76, 2014.

[10] Y. M. Al-Roomi, K. F. Hussain, and M. Al-Rifaie, "Performance of inhibitors on $\mathrm{CaCO}_{3}$ scale deposition in stainless steel \& copper pipe surface," Desalination, vol. 375, pp. 138-148, 2015.

[11] D. Peronno, H. Cheap-Charpentier, O. Horner, and H. Perrot, "Study of the inhibition effect of two polymers on calcium carbonate formation by fast controlled precipitation method and quartz crystal microbalance," Journal of Water Process Engineering, vol. 7, pp. 11-20, 2015.

[12] Z. Belarbi, J. Gamby, L. Makhloufi, B. Sotta, and B. Tribollet, "Inhibition of calcium carbonate precipitation by aqueous extract of Paronychia argentea," Journal of Crystal Growth, vol. 386, pp. 208-214, 2014.

[13] H. Cheap-Charpentier, D. Gelus, N. Perrot et al., "Antiscalant properties of Spergularia rubra and Parietaria officinalis aqueous solutions," Journal of Crystal Growth, vol. 443, pp. 43-49, 2016.

[14] B. El Ibrahimi, A. Jmiai, L. Bazzi, and S. El Issami, "Amino acids and their derivatives as corrosion inhibitors for metals and alloys," Arabian Journal of Chemistry, vol. 13, no. 1, 2017.

[15] B. Zhang, C. He, C. Wang, P. Sun, F. Li, and Y. Lin, "Synergistic corrosion inhibition of environment-friendly inhibitors on the corrosion of carbon steel in soft water," Corrosion Science, vol. 94, pp. 6-20, 2015.

[16] G. Vasyliev and V. Vorobiova, "Rape grist extract (Brassica napus) as a green corrosion inhibitor for water systems," Materials Today: Proceedings, vol. 6, pp. 178-186, 2019.

[17] L. Guangqing, M. Xue, and H. Yang, "Polyether copolymer as an environmentally friendly scale and corrosion inhibitor in seawater," Desalination, vol. 419, pp. 133-140, 2017. 
[18] M. A. Migahed, S. M. Rashwan, M. M. Kamel, and R. E. Habib, "Synthesis, characterization of polyaspartic acid-glycine adduct and evaluation of their performance as scale and corrosion inhibitor in desalination water plants," Journal of Molecular Liquids, vol. 224, pp. 849-858, 2016.

[19] H. Wang, M. Gao, Y. Guo, Y. Yang, and R. Hu, "A natural extract of tobacco rob as scale and corrosion inhibitor in artificial seawater," Desalination, vol. 398, pp. 198-207, 2016.

[20] R. Kelly, J. R. Scully, D. Shoesmith, and R. G. Buchheit, Electrochemical Techniques in Corrosion Science and Engineering, CRC Press, Boca Raton, FL, USA, 2002.

[21] Y. S. Herasymenko and H. S. Vasyl'ev, "A two-step method for the evaluation of corrosion rate in metals," Materials Science, vol. 45, no. 6, pp. 899-904, 2009.

[22] H. S. Vasyl'ev and Y. S. Herasymenko, "Corrosion meters of new generation based on the improved method of polarization resistance," Materials Science, vol. 52, pp. 722-731, 2017.

[23] H. S. Vasyl'Ev, "Measurement of polarization resistance with computer logging of results," Materials Science, vol. 48, pp. 694-696, 2013.

[24] F. Mansfeld, The Polarization Resistance Technique for Measuring Corrosion Currents, Springer, New York, NY, USA, 1976.

[25] V. Vorobyova, O. Chygyrynets, M. Skiba, T. Zhuk, I. Kurmakova, and O. Bondar, "A comprehensive study of grape cake extract and its active components as effective vapour phase corrosion inhibitor of mild steel," International Journal of Corrosion and Scale Inhibition, vol. 7, pp. 185-202, 2018.

[26] V. Vorobyova, O. Chygyrynetś, M. Skiba, I. Kurmakova, and O. Bondar, "Self-assembled monoterpenoid phenol as vapor phase atmospheric corrosion inhibitor of carbon steel," International Journal of Corrosion and Scale Inhibition, vol. 6, no. 4, pp. 485-503, 2017.

[27] V. I. Vorobyova, M. I. Skiba, A. S. Shakun, and S. V. Nahirniak, "Relationship between the inhibition and antioxidant properties of the plant and biomass wastes extracts-a review," International Journal of Corrosion and Scale Inhibition, vol. 8, pp. 150-178, 2019.

[28] V. Vorobyova, O. Chygyrynets, and M. Skiba, "4-hydroxy-3methoxybenzaldehyde as a volatile inhibitor on the atmospheric corrosion of carbon steel," Journal of Chemical Technology and Metallurgy, vol. 53, pp. 336-345, 2018.

[29] V. Vorobyova, M. Skiba, I. Trus, and S. Frolenkova, "Grape pomace extract as green vapor phase corrosion inhibitor," Chemistry and Chemical Technology, vol. 12, no. 3, pp. 410418, 2018.

[30] C. Woodward and E. A. Davidson, "Structure-function relationships of protein polysaccharide complexes: specific ionbinding properties," Proceedings of the National Academy of Sciences, vol. 60, no. 1, pp. 201-205, 1968.

[31] R. Aidoud, A. Kahoul, and F. Naamoune, "Inhibition of calcium carbonate deposition on stainless steel using olive leaf extract as a green inhibitor," Environmental Technology, vol. 38, no. 1, pp. 14-22, 2016.

[32] A. M. Abdel-Gaber, B. A. Abd-El-Nabey, E. Khamis, and D. E. Abd-El-Khalek, "Investigation of fig leaf extract as a novel environmentally friendly antiscalent for $\mathrm{CaCO}_{3}$ calcareous deposits," Desalination, vol. 230, no. 1-3, pp. 314-328, 2008 . 